\title{
Clinical Features And Neuroimaging Findings In Acute Cerebral Infarction Patients Using RAPID Artificial Intelligent (RAPID AI) Software Analysis - A Series Of 54 Cases
}

Ngoc Huy Nguyen ( $\nabla$ ngochuynguyen8888@gmail.com )

Phutho Department of Health, Vietnam

Minh Van Hoang

Hanoi University of Public Health

Anthony Rudd

Kings College

An Quang Nguyen

Phu Tho General Hospital

Thong Van Nguyen

Phu Tho General Hospital

Luc Quang Tran

Phu Tho General Hospital

Tuan Ngoc Minh Nguyen

Phu Tho General Hospital

\section{Research Article}

Keywords: stroke, risk factors, clinical signs, RAPID Al, Vietnam

Posted Date: May 20th, 2021

DOI: https://doi.org/10.21203/rs.3.rs-534389/v1

License: (c) (i) This work is licensed under a Creative Commons Attribution 4.0 International License.

Read Full License 


\section{Abstract}

Background: Stroke is the second leading cause of death and the leading cause of permanent disability globally. Vietnam is a developing country with a high prevalence of stroke but is under-resourced in terms of specialist staff able to interpret complex brain imaging.

Methods: A case series of 54 stroke patients admitted between October 2019 and October 2020 where thrombectomy was being considered and where 'Rapid' Artificial Intelligence (AI) was used to analyze images of stroke.

Results: The mean age of patients was $73.39 \pm 12.46$ years with $57 \%$ male. The most common risk factors were (76\%), atrial fibrillation (24\%), diabetes (20\%), alcohol (15\%), and smoking (9\%). The most common clinical signs were hemiparesis in $76 \%$ of the patients, followed by dysphasia in $50 \%$ and memory loss in $28 \%$ of the sample. $7 \%$ presented with dizziness and $7 \%$ with headache. $6 \%$ were unconscious on admission. ASPECTS evaluation showed that 24 (44\%) patients had good ASPECTS scores of $8-10,17$ (32\%) patients had ASPECTS scores of 5-7, and $13(24 \%)$ patients had ASPECTS scores of 0-4. The number of patients with an infarct core volume $<70 \mathrm{~mL}$ was 50 (93\%), while a mismatch volume of $>15 \mathrm{~mL}$ was observed in 31 (55\%) patients and $22(41 \%)$ patients had a mismatch ratio $>1.8$. The assessment of CT imaging of thrombi showed 51 cases of anterior cerebral circulation, including $13(24 \%)$ cases diagnosed as ICA, 30 (76\%) cases diagnosed as MCA, and $8(15 \%)$ cases diagnosed as SA. There were 10 cases of MCA-M1 (19\%), 7 cases of MCA-M2 and MCA-M4 (13\%) cases and 6 cases of MCA-M3 (11\%), respectively. There were three cases of posterior cerebral circulation, comprising Posterior Cerebral artery (PCA) infarction and two cases of Basilar Artery (BA) territory infarction.

Conclusions: RAPID Artificial Intelligent (RAPID Al) Software Analysis combined with clinical assessment can be used in identify the size and site of cerebral infarction and diffusion perfusion mismatch in routine clinical practice in Vietnam.

\section{Background}

Stroke is the second leading cause of death and the leading cause of disability globally [1]. In recent years, the burden of stroke associated with mortality, morbidity, and disability has been increasing across the world [2,3]. Risk factors associated with stroke can be divided into groups of modifiable and nonmodifiable features. The group of modifiable risk factors includes hypertension, smoking, diet, and physical inactivity, while the group of nonmodifiable risk factors comprises age, sex, family history, and race/ethnicity [4].

Vietnam is a developing country with nearly 100,000 million people, and strokes and stroke treatment are a major health burden in Vietnam [2, 5, 6]. About 200,000 people have a stroke each year with a $50 \%$ mortality rate, and with only $10 \%$ of patients returning to a normal life after stroke [6]. The facilities for the diagnosis and treatment of stroke are limited. The diagnosis of stroke is currently based on clinical 
findings combined with computer tomography imaging (CT) or magnetic resonance (MRI), however CT imaging or MRI facilities are not readily available and affordable in all hospitals and access to neuroradiology expertise is very limited.

Phu Tho Provincial General Hospital (GHP) is the leading provincial public hospital and the largest hospital in the northwest of Vietnam. The hospital has 1500 beds and well-equipped facilities for image diagnosis with both modern CT and MRI machines. The stroke center of GHP was established in 2018, containing 150 beds for inpatient treatment of people who suffered acute stroke and who require rehabilitation after stroke. In June 2019, the hospital began to use RAPID artificial intelligent (RAPID Al) software (iSchemaView, USA), for the imaging analysis of stroke characteristics based on an artificial intelligence technique.

This study presents the diagnostic and treatment features of stroke patients based on RAPID Al software assessment in Phu Tho Provincial General Hospital in Vietnam in 2019-2020.

\section{Methods}

\section{Study Design}

This study was a case series based on the data from electronic medical records of stroke patients admitted to Phu Tho Provincial General Hospital between October 2019 and October 2020, for whom Rapid Al was used to analyze images of stroke. The study was testing the practicability and value of using the technology in routine practice in Vietnam.

\section{Patients}

The stroke patients studied in this study had Rapid Al used for the diagnosis and analysis of cerebral images. All patients had CT or MRI scans performed within 24-48 $\mathrm{h}$ after the onset of stroke and were being considered for late thrombectomy. Information on the patients was collected using electronic medical records (Fig. 1). All patients gave written informed consent for participation in the study. Demographic Characteristics

Demographic data collected included age, sex, work status, living area, time onset of stroke, reasons for admission, hospitalization status, treatment duration, and discharge status.

Risk Factors for Stroke and Clinical Presentation

Information concerning risk factors for stroke, including age, sex, hypertension, diabetes, atrial fibrillation, smoking, and alcohol habits, was extracted from the electronic medical record profiles. The smoking habits, alcohol consumption, and onset time were determined in the present study by a neurologist questioning patients and/or relatives who had observed the onset and who were aware of the patient's recent health and clinical characteristics on admission were recorded

\section{Laboratory Investigations}


Diabetes was defined as a fasting blood glucose of greater than $7 \mathrm{mmol} / \mathrm{l}$ or use of hypoglycemic medications, and hyperlipidemia as serum levels of total cholesterol of greater than $5.2 \mathrm{mmol} / \mathrm{dl}$. Sociodemographic characteristics

Table 1. Sociodemographic characteristics of the studied patients. 


\begin{tabular}{|c|c|c|c|}
\hline \multirow[t]{2}{*}{ Sociodemographic Characteristics } & & \multicolumn{2}{|c|}{ Studied Patients } \\
\hline & & Frequency & Percent \\
\hline \multirow[t]{7}{*}{ Age } & $<40$ & 1 & 1.9 \\
\hline & $40-49$ & 1 & 1.9 \\
\hline & $50-59$ & 6 & 11.1 \\
\hline & $60-69$ & 10 & 18.5 \\
\hline & $70-79$ & 21 & 38.9 \\
\hline & $>80$ & 15 & 27.8 \\
\hline & Mean \pm SD & \multicolumn{2}{|c|}{$73.39 \pm 12.46$} \\
\hline \multirow[t]{2}{*}{ Gender } & Male & 31 & 57.4 \\
\hline & Female & 23 & 42.6 \\
\hline \multirow[t]{4}{*}{ Work status } & Farmers & 14 & 25.9 \\
\hline & Employees & 10 & 18.5 \\
\hline & Retired & 23 & 42.6 \\
\hline & Business work/free work & 7 & 13.0 \\
\hline \multirow[t]{2}{*}{ Living area } & Rural & 35 & 64.8 \\
\hline & Town/city & 19 & 35.2 \\
\hline \multirow[t]{3}{*}{ Time from onset to hospital arrival } & $0-6 \mathrm{~h}$ & 28 & 51.9 \\
\hline & $6-24 \mathrm{~h}$ & 24 & 44.4 \\
\hline & $>24 \mathrm{~h}$ & 2 & 3.7 \\
\hline \multirow[t]{3}{*}{ Hospital admission status } & Consciousness/awareness & 23 & 42.6 \\
\hline & Unconsciousness/unawareness & 27 & 50.0 \\
\hline & Coma & 4 & 7.4 \\
\hline \multirow[t]{3}{*}{ Hospital-discharged status } & Better & 40 & 74.0 \\
\hline & Worse & 7 & 13.0 \\
\hline & Died/worst & 7 & 13.0 \\
\hline
\end{tabular}

CT Imaging and Perfusion Imaging Analyzed Based using RAPID AI

On admission, ischemic stroke was diagnosed using clinical findings and brain imaging. The CT perfusion image characteristics were characterized in terms of ASPECTS, infarct core volume, and 
mismatch volume. Stroke patients were divided into four categories as follows: total anterior circulation infarcts, partial anterior circulation infarcts, posterior circulation infarcts, and lacunar infarcts. The imaging data of all patients were analyzed independently by two experienced neurologists. Lesions were divided into the following four categories: infarction of the anterior cerebral artery territory, middle cerebral artery territory, posterior cerebral artery territory, and vertebrobasilar artery territory. Cerebral imaging parameters were used to determine the locations of the lesions and then to identify infarctions in either a single vascular territory or multi-vascular territories (vascular territories $\geq 2$ ). Statistical Analysis

SPSS (version 22.0; IBM Corp., Armonk, NY, USA) was used for data analysis. Descriptive statistics were used to summarize sociodemographic and clinical information as well as subclinical data. Categorical variables were expressed as frequencies and percentages.

\section{Ethics Approval}

The study was approved by the Ethics Committee of Phu Tho Provincial General Hospital. The confidentiality of the information regarding patients was ensured in such a way that the data could only be used for the study purpose. The information obtained from the patients' electronic medical records is also presented only in a collective manner.

\section{Results}

\section{Patient Characteristics}

In total, 54 electronic medical records of patients diagnosed with ischemic stroke were identified. The age range of the 54 ischemic stroke patients was from 18 to 95 years of age. The mean age of the patients was $73.39 \pm 12.46$ years old, and the majority of patients $(85.2 \%)$ were in the age group of $>60$ years old. Male patients comprised 31 (57.4\%) of the total patients. The majority of the patients were retired $(42.6 \%)$ and living in rural areas (64.8\%). The time from onset to hospital arrival ranged from $0-6 \mathrm{~h}$ for 28 patients (51.9\%), from 6 to $24 \mathrm{~h}$ for 24 patients (44.4\%), and beyond $24 \mathrm{~h}$ for 2 patients (3.7\%). Patients admitted to hospital were mostly in states of unconsciousness $(50.0 \%)$ and coma (7.4\%), while $42.6 \%$ of patients were conscious. The number of patients discharged from the hospital who had made some recovery was 40 (74.0\%), while 7 (13\%) patients became worse or died (Table 2).

Risk Factors and Clinical Presentations of the Studied Patients

The most commonly identified risk factor was hypertension (75.9\%) followed by atrial fibrillation (24.1\%), diabetes $(20.4 \%)$, alcohol (14.8\%), and smoking (9.3\%). $76 \%$ of patients had hemiparesis $50 \%$ dysphasia $28 \%$. memory loss, $7 \%$ dizziness, and $7 \%$ headache. $5.6 \%$ of stroke patients had a poor prognosis with unconscious and near-death presentations (Table 3).

Table 3. Risk factors and clinical characteristics of the studied patients. 


\begin{tabular}{|c|c|c|c|}
\hline \multicolumn{2}{|c|}{ Risk Factors and Clinical Characteristics } & \multicolumn{2}{|c|}{ Studied Patients $(\mathrm{N}=54)$} \\
\hline & & Frequency & Percentage \\
\hline \multirow[t]{2}{*}{ Hypertension } & Yes & 41 & 75.9 \\
\hline & No & 13 & 24.1 \\
\hline \multirow[t]{2}{*}{ Diabetes } & Yes & 11 & 20.4 \\
\hline & No & 43 & 79.6 \\
\hline \multirow[t]{2}{*}{ Atrial fibrillation } & Yes & 13 & 24.1 \\
\hline & No & 41 & 75.9 \\
\hline \multirow[t]{2}{*}{ Smoking habits } & Yes & 5 & 9.3 \\
\hline & No & 49 & 90.7 \\
\hline \multirow[t]{2}{*}{ Alcohol habits } & Yes & 8 & 14.8 \\
\hline & No & 46 & 85.2 \\
\hline \multirow[t]{7}{*}{ Clinical presentations } & Hemiparesis & 41 & 75.9 \\
\hline & Memory loss & 15 & 27.8 \\
\hline & Dysarthria & 27 & 50.0 \\
\hline & Dizziness & 4 & 7.4 \\
\hline & Headache & 4 & 7.4 \\
\hline & Unconsciousness & 3 & 5.6 \\
\hline & Nearly died & 3 & 5.6 \\
\hline
\end{tabular}

High blood pressure was seen in $48(88.9 \%)$ of the 54 recorded stroke patients, the median systolic blood pressure was $151.22 \pm 22.9 \mathrm{mmHg}$. The red blood cells of male and female patients mostly showed normal concentrations at $77.4 \%$ and $82.6 \%$, respectively. Similarly, $45(83.3 \%)$ patients were normal in terms of their triglyceride level and $9(16.7 \%)$ patients were high in triglyceride. A prevalence of elevated blood glucose was observed in $40.7 \%$ patients, while the prevalence of high cholesterol was $33.3 \% .3$ (5.6\%) patients had a low platelet count. Only two (3.7\%) patients were high in INR, while most of the studied patients $(96.3 \%)$ had a normal INR (Table 4$)$.

Table 4. Distribution of patients' laboratory results. 


\begin{tabular}{|c|c|c|c|c|c|}
\hline \multirow[t]{2}{*}{ Characteristics } & & \multicolumn{4}{|c|}{ Studied Patients } \\
\hline & & Low & Normal & High & Mean \pm SD \\
\hline Blood pressure & & $1(1.9 \%)$ & $5(9.3 \%)$ & $48(88.9)$ & $151 \pm 23 \mathrm{mmHg}$ \\
\hline \multirow[t]{2}{*}{ Red blood cells (Tera/L) } & Male & $6(19.4 \%)$ & $24(77.42 \%)$ & $1(3.23 \%)$ & $4.94 \pm 0.68$ \\
\hline & Female & $2(8.7 \%)$ & $19(82.6 \%)$ & $2(8.7 \%)$ & $4.3 \pm 0.46$ \\
\hline Blood glucose (mg/dL) & & $2(3.7 \%)$ & $30(55.6 \%)$ & $22(40.7 \%)$ & $2.37 \pm 0.56$ \\
\hline Cholesterol (mg/dL) & & $10(18.5 \%)$ & $26(48.1 \%)$ & $18(33.3 \%)$ & $2.14 \pm 0.71$ \\
\hline Platelet count & & $3(5.6 \%)$ & $51(94.4 \%)$ & 0 & $1.94 \pm 0.23$ \\
\hline INR & & 0 & $52(96.3 \%)$ & $2(3.7 \%)$ & $1.04 \pm 0.19$ \\
\hline Triglyceride & & 0 & 45 (83.3\%) & $9(16.7 \%)$ & $1.58 \pm 0.85$ \\
\hline
\end{tabular}

3.3. CT Perfusion Images Based on RAPID AI Analysis

The distribution of the ASPECTS score is given in Table 5. Only 4 (7.4\%) patients had an infarct core volume greater than $70 \mathrm{~mL}$ compared to $50(92.6 \%)$ patients with an infarct core volume smaller than 70 $\mathrm{mL}$. The mismatch volume was greater than $15 \mathrm{~mL}$ in 31 (54.7\%) patients, while 23 (45.3\%) patients had a mismatch smaller than $15 \mathrm{~mL}$. In total, $32(59.3 \%)$ patients had a mismatch ratio under 1.8 , but 22 (40.7\%) patients had a mismatch ratio over 1.8 (Table 5).

Table 5. Distribution of studied patients based on the RAPID Al perfusion analysis. 


\begin{tabular}{|c|c|c|c|c|c|}
\hline \multicolumn{2}{|c|}{ Radiological measures } & \multicolumn{3}{|c|}{ Time from Onset to Hospital } & \multirow[t]{2}{*}{ Frequency } \\
\hline & & $0-6 \mathrm{~h}$ & $6-24 h$ & $>24 \mathrm{~h}$ & \\
\hline \multirow[t]{4}{*}{ ASPECTS } & $8-10$ (good) & $14(50 \%)$ & $10(41.7 \%)$ & 0 & $24(44.4 \%)$ \\
\hline & 5-7 (bad) & $8(28.6 \%)$ & $9(37.5 \%)$ & 0 & $17(31.5 \%)$ \\
\hline & $0-4$ (worst) & $6(21.4 \%)$ & $5(20.8 \%)$ & $2(100 \%)$ & $13(24.1 \%)$ \\
\hline & Total & $28(100 \%)$ & $24(100 \%)$ & $2(100 \%)$ & $54(100 \%)$ \\
\hline \multirow[t]{3}{*}{ Infarct core volume } & $<70 \mathrm{~mL}$ & $26(92.9 \%)$ & $23(95.8 \%)$ & $1(50 \%)$ & $50(92.6 \%)$ \\
\hline & $\geq 0 \mathrm{~mL}$ & $2(7.1 \%)$ & $1(4.2 \%)$ & $1(50 \%)$ & $4(7.4 \%)$ \\
\hline & Total & $28(100 \%)$ & $24(100 \%)$ & $2(100 \%)$ & $54(100 \%)$ \\
\hline \multirow[t]{3}{*}{ Mismatch volume } & $<15 \mathrm{~mL}$ & $14(50 \%)$ & $7(29.2 \%)$ & $2(100 \%)$ & $23(45.3 \%)$ \\
\hline & $\geq 15 \mathrm{~mL}$ & $14(50 \%)$ & $17(70.8 \%)$ & 0 & $31(54.7 \%)$ \\
\hline & Total & $28(100 \%)$ & $24(100 \%)$ & $2(100 \%)$ & $54(100 \%)$ \\
\hline \multirow[t]{3}{*}{ Mismatch ratio } & $<1.8$ & $19(67.9 \%)$ & $12(50 \%)$ & $1(50 \%)$ & $32(59.3 \%)$ \\
\hline & $\geq 1.8$ & $9(31.1 \%)$ & $12(50 \%)$ & $1(50 \%)$ & $22(40.7 \%)$ \\
\hline & Total & $28(100 \%)$ & $24(100 \%)$ & $2(100 \%)$ & 54 (100\%) \\
\hline
\end{tabular}

In our study, we observed 51 cases of anterior cerebral circulation including $13(24.07 \%)$ cases that were due to ICA occlusion, 30 (75.93\%) cases diagnosed as MCA occlusion, and 8 (14.81\%) cases diagnosed as Small Artery occlusion (SA). Of these, the number of cases of MCA-M1 was $10(18.5 \%)$, the number of cases of each MCA-M2 and MCA-M4 was 7 (13\%), and the number of cases of MCA-M3 was $6(11 \%)$, respectively. There were only three cases of posterior cerebral circulation, including one $(1.9 \%)$ case of PCA and two (3.7\%) cases of BA. In total, 28 stroke patients were admitted to the hospital within the first $6 \mathrm{~h}$ after onset, and 24 patients were admitted within 6 to $24 \mathrm{~h}$. Only two patients were admitted beyond $24 \mathrm{~h}$ (Table 6).

Table 6. Cerebral occlusive position based on the RAPID Al analysis $(n=54)$. 


\begin{tabular}{|c|c|c|c|c|c|}
\hline \multirow[t]{2}{*}{ Occlusal Position } & & \multicolumn{3}{|c|}{$\begin{array}{l}\text { Time from Onset to Hospital } \\
\text { Admission }\end{array}$} & \multirow[t]{2}{*}{ Frequency } \\
\hline & & $0-6 \mathrm{~h}$ & $6-24$ & $>24 \mathrm{~h}$ & \\
\hline \multirow[t]{6}{*}{$\begin{array}{l}\text { Anterior cerebral circulation }(n= \\
51)\end{array}$} & $\begin{array}{l}\text { MCA- } \\
\text { M1 }\end{array}$ & $6(21.4 \%)$ & $4(16.7 \%)$ & 0 & $\begin{array}{l}10 \\
(18.5 \%)\end{array}$ \\
\hline & $\begin{array}{l}\text { MCA- } \\
\text { M2 }\end{array}$ & $3(10.7 \%)$ & $3(12.5 \%)$ & $1(50.0 \%)$ & $7(13 \%)$ \\
\hline & $\begin{array}{l}\text { MCA- } \\
\text { M3 }\end{array}$ & $3(10.7 \%)$ & $2(8.3 \%)$ & $1(50.0 \%)$ & $6(11 \%)$ \\
\hline & $\begin{array}{l}\text { MCA- } \\
\text { M4 }\end{array}$ & $3(10.7 \%)$ & $4(16.7 \%)$ & 0 & $7(13 \%)$ \\
\hline & ICA & $7(25.0 \%)$ & $6(25.0 \%)$ & 0 & $13(24 \%)$ \\
\hline & SA & $5(17.9 \%)$ & $3(12.5 \%)$ & 0 & $8(14.8 \%)$ \\
\hline \multirow{2}{*}{$\begin{array}{l}\text { Posterior cerebral circulation }(n= \\
\text { 3) }\end{array}$} & PCA & $1(3.6 \%)$ & 0 & 0 & $1(1.9 \%)$ \\
\hline & BA & 0 & $2(8.3 \%)$ & 0 & $2(3.7 \%)$ \\
\hline Total & & $28(100 \%)$ & $24(100 \%)$ & $2(100 \%)$ & $54(100 \%)$ \\
\hline
\end{tabular}

The cerebral occlusive position M1: spheroidal or horizontal segment; M2: insular segment; M3: opercular segment; M4: cortical segment; PCA: posterior cerebral artery; ICA: internal carotid artery; SA: small artery; BA: basal artery.

\section{Discussion}

Phu Tho Provincial General Hospital was the first hospital in to Vietnam introduce RAPID Al technology for the diagnosis and treatment of stroke patientsThis study presents the results of the diagnosis and treatment of stroke patients for whom RAPID Al combined with neuroimaging was used for the detection, characterization, and prognostication of acute strokes. Al technology is a rapidly developing field and represents a promising avenue for fast and efficient imaging analysis [7]. RAPID Al has been approved and certified by the FDA for perfusion imaging and is currently used in 50 countries. RAPID Al software can be used for perfusion imaging in stroke. The RAPID Al software was validated in the DEFUSE 2 study in 2012 and received FDA approval in 2013 [8]. RAPID software analyzes CT and MRI perfusion within 3 minutes and generates colorimetric perfusion maps of stroke penumbra as well as the core mismatch volume and mismatch ratio [9]. The penumbra mismatch sensitivity is $100 \%$ and specificity is $91 \%$ [1013]. RAPID Al technology was used in the recent large LVO ET trials EXTEND IA, SWIFT PRIME, CRISP, DEFUSE 2 and 3 , and DAWN $[8,10,14-16]$.

Stroke incidence increases with age and is more common in males [17]. The analysis of this cohort of 54 patients' electronic medical records were the first to be assessed using Al in Phu Tho Provincial General Hospital, Vietnam from October 2019 to June 2020. The results of our study agree with those of previous 
studies in terms of demographic characteristics conducted by Albers et al. in Gondar University Hospital [18], Tirschwell et al. in Danang Hospital [19], and Yue in China [20] 21].

The time from symptom onset to hospital arrival (time to hospital) is a key factor for delivering effective treatment and improved outcomes of stroke patients, especially for patients with ischemic stroke. Our results for time to hospital showed that about half of patients arrive after six hours and are therefore less likely to be eligible for reperfusion treatment. If outcomes are to improve in Vietnam the systems for prehospital care in terms of patient and population awareness of the symptoms of stroke and emergency medical services need to improve. The patients who do present are predominantly very severe stroke with over half having reduced levels of consciousness. These results were similar to those of a study in Hong Kong [22] and Shanghai [23], which showed that $56.3 \%$ and $51.9 \%$ of patients arrived at a hospital within $6 \mathrm{~h}$ after the first symptom of stroke. Previous studies have presented a median arrival time that varied

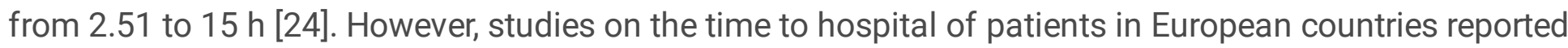
that the majority of patients arrived within $3 \mathrm{~h}$ of onset, earlier than in Asian countries, which is due to the higher rate of ambulance transport of stroke patients and better stroke awareness knowledge in these countries [25].

In our study, we found that the most common risk factor was hypertension, identified in $75.9 \%$ of patients, followed by atrial fibrillation in $24.1 \%$ of patients, and diabetes in $20.4 \%$ of patients. These results align with previous studies indicating that uncontrolled hypertension is the most important risk factor for stroke in developing and developed countries [26]. This may reflect the fact that hypertension has been identified as the most prevalent modifiable risk factor and is a powerful modifiable risk factor. On the other hand, the numbers of stroke patients with smoking and alcohol habits in this study were lower $(<$ 15\%) than in other studies, [27].

Hemiparesis and dysarthria were two of the most common clinical presentations of stroke in our study, at $75.9 \%$ and $50 \%$ of the total, respectively. This is similar to cohorts reported from Egypt [28] and India [29], which showed that $76.1 \%$ of patients had hemiparesis and $60 \%$ of patients had dysarthria. Memory loss commonly occurs as a result of stroke and was observed in $27.8 \%$ of patients in our study. Other investigators have reported a dementia incidence of approximately $25 \%$ at 3 months after ischemic stroke. In the current study, a small number of patients suffered from dizziness and headache (7.4\%), and unconsciousness and near death (5.6\%). These results also agree with the results of El Tallawy [28].

There was a variety in the laboratory tests requested as this depends on the stroke clinicians rather than a formal protocol In our study, the laboratory tests included BP, RBC, BG, cholesterol, PC, INR, and triglyceride. These tests were examined to evaluate patients before the administration of tPA. Some of the tests are necessary to determine suitability for intravenous thrombolysis but some are often unnecessary and just delay commencement of acute treatments. [32].

The application of RAPID Al to read CT perfusion images was first applied in Phu Tho Provincial General Hospital, Vietnam, in June 2019. RAPID Al technology processing takes within 3 minutes to send the results of ASPECTS, infarct core volume, mismatch volume, and mismatch ratio to PACS and RAPID 
mobile apps. This application was developed by an experienced neurologist, Greg Alber [33]. The ASPECTS is a 10-point quantitative topographic CT scan score used for patients with middle cerebral artery (MCA) stroke [34]. Our study showed the ASPECTS score was good in $44.4 \%$ of patients, compared with $31.5 \%$ showing a bad score and $24.1 \%$ showing the worst possible score. The assessment of the ASPECTS score has been used to direct therapies. Those with a low ASPECTS score, suggesting a large MCA infarction, can be excluded from futile intra-arterial treatments, which are unlikely to result in patients gaining functional independence and increase the risk of hemorrhage [34]. The infarct core volume shows the part of the AIS which was already infarcted or was irrevocably destined to infarct regardless of reperfusion [35]. The inclusion criteria used to select patients eligible for interventional thrombectomy in the case of patients admitted to hospital within or beyond $6 \mathrm{~h}$ onset include an initial infarct volume of $<70 \mathrm{~mL}$, a ratio of ischemic penumbra to infarct core of $\geq 1.8$, and an absolute mismatch of $\geq 15 \mathrm{~mL}[36,37]$. Our results showed that the majority of patients had an infarct core volume of $<70 \mathrm{~mL}$, at $50(92.6 \%)$ patients; a mismatch volume of $>15 \mathrm{~mL}$ was observed in $31(54.7 \%)$ patients, and $22(40.7 \%)$ patients had a mismatch ratio of $>1.8$. Previous studies have indicated that the automated RAPID Al system is sufficiently accurate and fast to be used for routine care as well as in clinical trials [11, 38]. The evidence of using RAPID showed the diffusion-perfusion mismatch identified by RAPID was in agreement with the observation of a human reader in 60 cases (95.2\%) and in disagreement in 3 cases (4.8\%, 3 false positives) [11]. RAPID was able to identify mismatches with $100 \%$ sensitivity and $91 \%$ specificity (false positive rate $=9.1 \%$, false negative rate $=0 \%$ ) in analyses with the observations of the human reader as a ground truth [11].

The RAPID software enabled information about the location, size, and whether there was any potentially salvageable brain enabling the physicians to make decisions on the suitable treatment, whether thrombolysis or thrombectomy [39]. The diagnostic evaluation of occlusive thrombi on noninvasive studies now constitutes an integral component of acute stroke management [39]. In a hospital with limited access to neuroradiology 24 hours a day, seven days a week, such a facility is of critical importance and has huge potential to improve the quality of clinical care in hospitals and countries with limited resources. Clearly, this needs to be combined with improving public awareness that stroke is a treatable condition if they get to hospital quickly after the onset of symptoms, and an improved emergency medical service. The current poor outcomes with a $50 \%$ mortality and only $10 \%$ making a full recovery are unacceptable. Using modern technology such as RAPID or similar artificial intelligence systems will be important to improve outcomes.

\section{Conclusions}

The majority of studied patients in this study had severe stroke and presented late. While work is needed to improve prehospital care the value of artificial intelligence software to identify which patients might still benefit from reperfusion will be important, particularly in resource poor settings to improve the quality of care and outcomes. This is the first study to present results on the diagnostic and treatment features of stroke patients in Vietnam for whom RAPID Al was used for their screening and management. 


\section{Declarations}

\section{Acknowledgments}

We thank all our colleagues at the Department of Radiology and Centre of Stroke in Phutho General Hospital.

Funding: This research did not receive any specific grant from funding agencies in the public, commercial or not-for-profit sectors.

Author Contributions: N.N.H. and H.M.V. designed the study, analyzed the data, and wrote, edited, and reviewed the manuscript. N.A.Q., N.T.V, and T.L.Q. performed the experiments, acquired and analyzed the data. A.R and T.N.M.N wrote, edited, and reviewed the manuscript. All authors have read and agreed to the published version of the manuscript.

\section{Corresponding author}

Correspondence: minhtuannn@hvu.edu.vn; ngochuynguyen@8888gmail.com

\section{Ethics declarations}

\section{Ethics approval and consent to participate}

The study was conducted according to the guidelines of the Declaration of Helsinki, and approved by the Ethics Committee of Phu Tho General Hospital (Decision of 1533/QĐ-BV on October 05, 2018)

\section{Consent for publication}

Not applicable.

\section{Competing interests}

The authors declare that they have no competing interests.

Data Availability Statement: All relevant data are available in the article and/or supplemental file. Due to privacy and other restrictions, the primary data cannot be made openly available. Details about requesting access to the data are available from the corresponding author.

\section{References}

1. Donkor, E.S. Stroke in the century: A snapshot of the burden, epidemiology, and quality of life. Stroke Res. Treat. 2018, 2018, 1-10.

2. Feigin, V.L.; Norrving, B.; Mensah, G.A. Global burden of stroke. Circ. Res. 2017, 120, 439-448. 
3. Feigin, V.L.; Krishnamurthi, R.V.; Parmar, P.; Norrving, B.; Mensah, G.A.; Bennett, D.A.; Barker-Collo, S.; Moran, A.E.; Sacco, R.L.; Truelsen, T. Update on the global burden of ischemic and hemorrhagic stroke in 1990-2013: The GBD 2013 study. Neuroepidemiology 2015, 45, 161-176.

4. Boehme, A.K.; Esenwa, C.; Elkind, M.S. Stroke risk factors, genetics, and prevention. Circ. Res. 2017, $120,472-495$.

5. Ng, J.C.; Churojana, A.; Pongpech, S.; Vu, L.D.; Sadikin, C.; Mahadevan, J.; Subramaniam, J.; Jocson, V.E.; Lee, W. Current state of acute stroke care in Southeast Asian countries. Interv. Neuroradiol. 2019, 25, 291-296.

6. Nguyen, N.; Tran, L.; Bui, L.; Theo, V.; Nguyen, H.; Ngo, A. Estimation of Vietnam national burden of disease 2008. Asia Pac. J. Public Health 2008, 26, 527.

7. Lee, E.-J.; Kim, Y.-H.; Kim, N.; Kang, D.-W. Deep into the brain: Artificial intelligence in stroke imaging. J. Stroke 2017, 19, 277.

8. Lansberg, M.G.; Straka, M.; Kemp, S.; Mlynash, M.; Wechsler, L.R.; Jovin, T.G.; Wilder, M.J.; Lutsep, H.L.; Czartoski, T.J.; Bernstein, R.A. MRI profile and response to endovascular reperfusion after stroke (DEFUSE 2): A prospective cohort study. Lancet Neurol. 2012, 11, 860-867.

9. Murray, N.M.; Unberath, M.; Hager, G.D.; Hui, F.K. Artificial intelligence to diagnose ischemic stroke and identify large vessel occlusions: A systematic review. J. Neurointerv. Surg. 2020, 12, 156-164.

10. Albers, G.W.; Marks, M.P.; Kemp, S.; Christensen, S.; Tsai, J.P.; Ortega-Gutierrez, S.; McTaggart, R.A.; Torbey, M.T.; Kim-Tenser, M.; Leslie-Mazwi, T. Thrombectomy for stroke at 6 to 16 hours with selection by perfusion imaging. N. Engl. J. Med. 2018, 378, 708-718.

11. Straka, M.; Albers, G.W.; Bammer, R. Real-time diffusion-Perfusion mismatch analysis in acute stroke. J. Magn. Reson. Imaging 2010, 32, 1024-1037.

12. Austein, F.; Riedel, C.; Kerby, T.; Meyne, J.; Binder, A.; Lindner, T.; Huhndorf, M.; Wodarg, F.; Jansen, 0. Comparison of perfusion CT software to predict the final infarct volume after thrombectomy. Stroke 2016, 47, 2311-2317.

13. Saver, J.L.; Goyal, M.; Bonafe, A.; Diener, H.-C.; Levy, E.I.; Pereira, V.M.; Albers, G.W.; Cognard, C.; Cohen, D.J.; Hacke, W. Stent-retriever thrombectomy after intravenous t-PA vs. t-PA alone in stroke. N. Engl. J. Med. 2015, 372, 2285-2295.

14. Nogueira, R.G.; Jadhav, A.P.; Haussen, D.C.; Bonafe, A.; Budzik, R.F.; Bhuva, P.; Yavagal, D.R.; Ribo, M.; Cognard, C.; Hanel, R.A. Thrombectomy 6 to 24 hours after stroke with a mismatch between deficit and infarct. N. Engl. J. Med. 2018, 378, 11-21.

15. Campbell, B.C.; Mitchell, P.J.; Kleinig, T.J.; Dewey, H.M.; Churilov, L.; Yassi, N.; Yan, B.; Dowling, R.J.; Parsons, M.W.; Oxley, T.J. Endovascular therapy for ischemic stroke with perfusion-imaging selection. N. Engl. J. Med. 2015, 372, 1009-1018.

16. Lansberg, M.G.; Christensen, S.; Kemp, S.; Mlynash, M.; Mishra, N.; Federau, C.; Tsai, J.P.; Kim, S.; Nogueria, R.G.; Jovin, T. Computed tomographic perfusion to predict response to recanalization in ischemic stroke. Ann. Neurol. 2017, 81, 849-856. 
17. Roger. Executive Summary: Heart Disease and Stroke Statistics-2012 Update: A Report From the American Heart Association (vol 125, pg 188, 2012). Circulation 2012, 125, E1001.

18. Tirschwell, D.L.; Ton, T.G.; Ly, K.A.; Van Ngo, Q.; Vo, T.T.; Pham, C.H.; Longstreth, W.T.; Fitzpatrick, A.L. A prospective cohort study of stroke characteristics, care, and mortality in a hospital stroke registry in Vietnam. BMC Neurol. 2012, 12,1-11.

19. Albers, G.; Bittar, N.; Young, L.; Hattemer, C.; Gandhi, A.; Kemp, S.; Hall, E.; Morton, D.; Yim, J. Clinical characteristics and management of acute stroke in patients with atrial fibrillation admitted to US university hospitals. Neurology 1997, 48, 1598-1604.

20. Yue, Y.H.; Li, Z.Z.; Hu, L.; Zhu, X.Q.; Xu, X.S.; Sun, H.X.; Wan, Z.W.; Xue, J.; Yu, D.H. Clinical characteristics and risk score for poor clinical outcome of acute ischemic stroke patients treated with intravenous thrombolysis therapy. Brain Behav. 2019, 9, e01251.

21. Gao, X.; Zhang, J.; Peng, Y.; Fan, H.; Chen, M.; Xu, T.; Zhang, Y. Admission clinical characteristics and early clinical outcomes among acute ischemic stroke patients. J. Biomed. Res. 2012, 26, 152-158, doi:10.7555/JBR.26.20110129.

22. Cheung, R. Hong Kong patients' knowledge of stroke does not influence time-to-hospital presentation. J. Clin. Neurosci. 2001, 8, 311-314.

23. Fang, J.; Yan, W.; Jiang, G.-X.; Li, W.; Cheng, Q. Time interval between stroke onset and hospital arrival in acute ischemic stroke patients in Shanghai, China. Clin. Neurol. Neurosurg. 2011, 113, 85-88.

24. Maestroni, A.; Mandelli, C.; Manganaro, D.; Zecca, B.; Rossi, P.; Monzani, V.; Torgano, G. Factors influencing delay in presentation for acute stroke in an emergency department in Milan, Italy. Emerg. Med. J. 2008, 25, 340-345.

25. Adeoye, O.; Lindsell, C.; Broderick, J.; Alwell, K.; Jauch, E.; Moomaw, C.J.; Flaherty, M.L.; Pancioli, A.; Kissela, B.; Kleindorfer, D. Emergency medical services use by stroke patients: A population-based study. Am. J. Emerg. Med. 2009, 27, 141-145.

26. Chockalingam, A.; Campbell, N.R.; Fodor, J.G. Worldwide epidemic of hypertension. Can. J. Cardiol. 2006, 22, 553-555.

27. Xu, W.-H.; Zhang, X.-L.; Gao, Y.-T.; Xiang, Y.-B.; Gao, L.-F.; Zheng, W.; Shu, X.-O. Joint effect of cigarette smoking and alcohol consumption on mortality. Prev. Med. 2007, 45, 313-319.

28. El Tallawy, H.N.; Farghaly, W.M.; Badry, R.; Hamdy, N.A.; Shehata, G.A.; Rageh, T.A.; Metwally, N.A.; Hassan, E.M.; Elsayed, S.S.; Yehia, M.A.; et al. Epidemiology and clinical presentation of stroke in Upper Egypt (desert area). Neuropsychiatr. Dis. Treat. 2015, 11, 2177.

29. Siddique, M.A.N.; Nur, Z.; Mahbub, M.S.; Alam, M.B.; Miah, M.T. Clinical presentation and epidemiology of stroke: A study of 100 cases. J. Med. 2009, 10, 86-89.

30. Bowry, R.; Navalkele, D.D.; Gonzales, N.R. Blood pressure management in stroke: Five new things. Neurol. Clin. Pract. 2014, 4, 419-426.

31. Qureshi, A.I.; Ezzeddine, M.A.; Nasar, A.; Suri, M.F.K.; Kirmani, J.F.; Hussein, H.M.; Divani, A.A.; Reddi, A.S. Prevalence of elevated blood pressure in 563704 adult patients with stroke presenting to the ED in the United States. Am. J. Emerg. Med. 2007, 25, 32-38. 
32. Kleindorfer, D.; Kissela, B.; Schneider, A.; Woo, D.; Khoury, J.; Miller, R.; Alwell, K.; Gebel, J.; Szaflarski, J.; Pancioli, A. Eligibility for recombinant tissue plasminogen activator in acute ischemic stroke: $A$ population-based study. Stroke 2004, 35, e27-e29.

33. Albers, G.W.; Wald, M.J.; Mlynash, M.; Endres, J.; Bammer, R.; Straka, M.; Maier, A.; Hinson, H.E.; Sheth, K.N.; Taylor Kimberly, W. Automated calculation of Alberta Stroke Program Early CT Score: Validation in patients with large hemispheric infarct. Stroke 2019, 50, 3277-3279.

34. Barber, P.A.; Demchuk, A.M.; Zhang, J.; Buchan, A.M.; Group, A.S. Validity and reliability of a quantitative computed tomography score in predicting outcome of hyperacute stroke before thrombolytic therapy. Lancet 2000, 355, 1670-1674.

35. Sakai, Y.; Delman, B.N.; Fifi, J.T.; Tuhrim, S.; Wheelwright, D.; Doshi, A.H.; Mocco, J.; Nael, K. Estimation of Ischemic Core Volume Using Computed Tomographic Perfusion: Bayesian Versus Singular Value Deconvolution Postprocessing. Stroke 2018, 49, 2345-2352.

36. Yu, W.; Jiang, W.-J. A simple imaging guide for endovascular thrombectomy in acute ischemic stroke: From time window to perfusion mismatch and beyond. Front. Neurol. 2019, 10, 502.

37. Casetta, I.; Fainardi, E.; Saia, V.; Pracucci, G.; Padroni, M.; Renieri, L.; Nencini, P.; Inzitari, D.; Morosetti, D.; Sallustio, F. Endovascular Thrombectomy for Acute Ischemic Stroke Beyond 6 Hours From Onset: A Real-World Experience. Stroke 2020, 51, 2051-2057.

38. Albers, G.W.; Thijs, V.N.; Wechsler, L.; Kemp, S.; Schlaug, G.; Skalabrin, E.; Bammer, R.; Kakuda, W.; Lansberg, M.G.; Shuaib, A.; et al. Magnetic resonance imaging profiles predict clinical response to early reperfusion: The diffusion and perfusion imaging evaluation for understanding stroke evolution (DEFUSE) study. Ann. Neurol. Off. J. Am. Neurol. Assoc. Child Neurol. Soc. 2006, 60, 508-517.

39. Gasparian, G.G.; Sanossian, N.; Shiroishi, M.S.; Liebeskind, D.S. Imaging of occlusive thrombi in acute ischemic stroke. Int. J. Stroke 2015, 10, 298-305.

\section{Table 2}

Table 2 is not available with this version

\section{Figures}




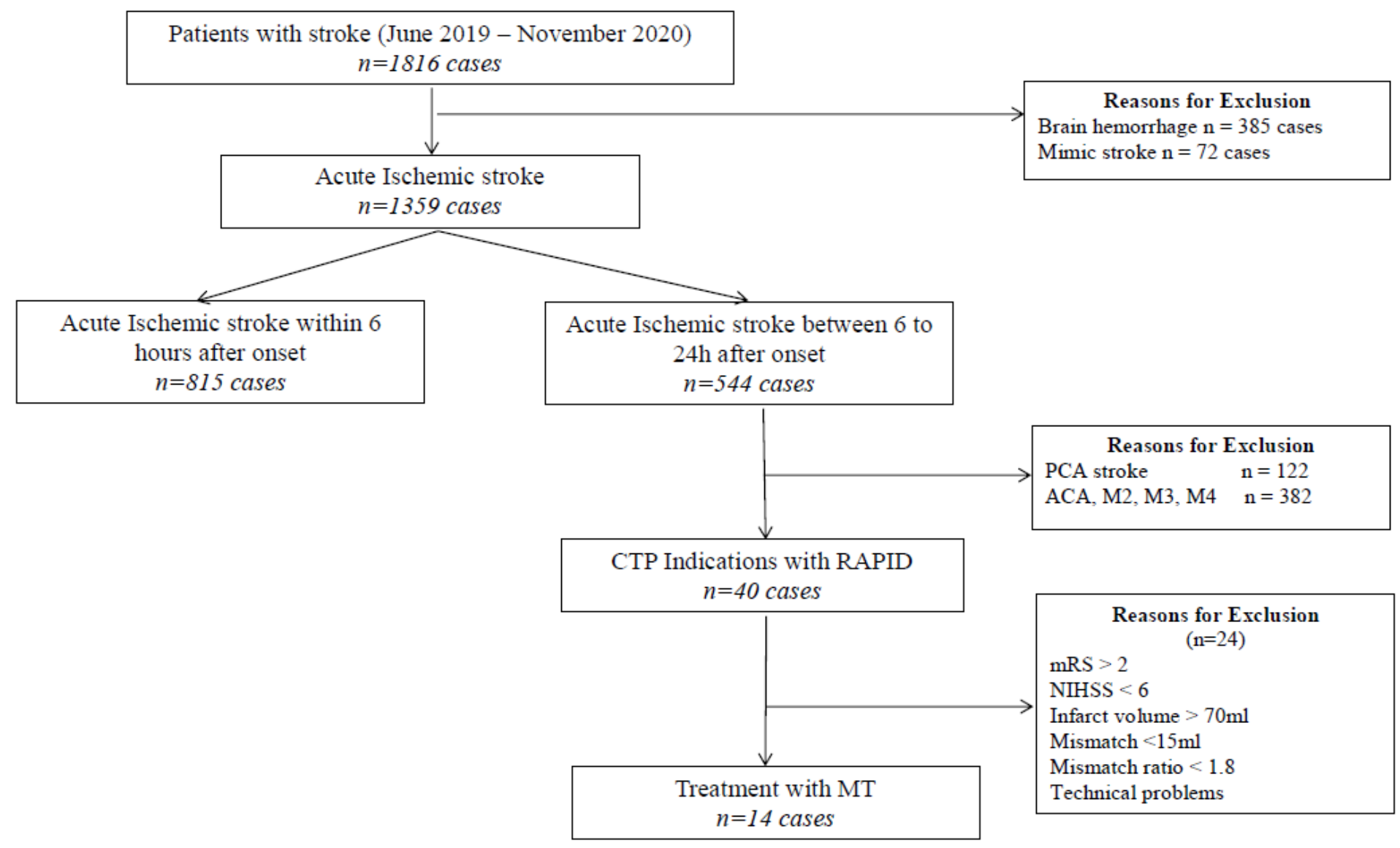

\section{Figure 1}

Flow diagram of the study and selected eligible patients based on RAPID 